\title{
Exploration of "Three Types" Talent Cultivation of Material Speciality Based on Open Laboratory
}

\author{
Tu-sheng HE, Zai-bo LI and Yang LIU
}

School of Civil Engineering, Shaoguan University, Shaoguan 512005, Guangdong, China

Keywords: Open laboratory, Applied type, Innovative type, Entrepreneurial type, Cultivating talents.

\begin{abstract}
Applied type, innovative type and entrepreneurial type "Three Types" talent is the target of cultivating talents based on the development orientation of Shaoguan University, and the opening laboratory is the key to achieve the goal of the "Three Types" cultivating talents. Firstly, the main problems existing in university laboratories are analyzed, and the necessity of building an open laboratory is analyzed. Then, specific measures are put forward for the construction of an open laboratory for the inorganic nonmetallic materials engineering of Shaoguan University. Finally, the beneficial effects of the open laboratory are summed up in the last three years' exploration and practice of the open laboratory.
\end{abstract}

\section{开放实验室对材料专业 “三型” 人才培养的探索 \\ 贺图升, 黎载波, 刘洋 \\ 韶关学院 土木工程学院, 韶关 512005, 广东, 中国}

关键词：开放实验室；应用型；创新型；创业型；人才培养

摘要：应用型、创新型、创业型 “三型” 人才是韶关学院基于自身发展定位提出来的人才培 养目标, 而开放实验室是实现 “三型” 人才培养目标的关键。首先分析了目前高校实验室存 在的主要问题以及建设开放实验室的必要性, 然后针对韶关学院无机非金属材料工程专业提 出了建设开放实验室的具体措施, 最后结合近三年开放实验室的探索与实践情况总结了开放 实验室的有益效果。

\section{1. 高校实验室存在的主要问题}

\section{1 实验教学内容陈旧, 方法落后}

以教学方法而言, 实验教学一直强调三基能力, 培养学生的基本知识、基本技能、基本 操作是需要的, 但强调过分了就适得其反。实验讲义写得详详细细, 学生实验“照方抓药”, 按规定的实验方法和步骤, 在规定的时间内机械地完成实验任务, 使学生一直处于被动状 态, 这种被动式的学习, 学生感到枯燥乏味, 激发不了学生的兴趣和创新欲望, 这就大大束 缚了学生思维能力和创造能力的培养。从效果上看, 实验虽然做了不少, 但很多同学却不会 设计实验, 也不会观察、分析问题, 有的甚至不会选用基本仪器。在教学体制上同一模式造 就学生, 一门实验课总学时数以及每个实验的学时数均有限, 每个学生都必须在规定时间内 完成, 用此种模式造就出来的学生仅仅只能分出优、良、中、差, 不利于发挥学生的自主性 和创造性, 不利于发挥富于创新能力学生的才能和造就他们的才能。随着高等教育的发展, 各学科、各专业课之间越来越多的相互渗透, 多学科综合的实验内容、实验技术、实验方法 也难以进入依附于理论课的实验中去, 在旧的传统的教学指导思想下, 很难培养学生的创新 能力。 


\section{2 实验仪器设备使用效率低}

高校对实验室的建设投入了大量的财力、物力和人力, 然而, 设备利用率低是目前高校 实验室普遍存在的问题。目前高校实验室设计与建设存在缺乏系统性, 思路不清晰, 定位不 明确等问题, 没有从学校定位与学科专业建设的角度进行整体性和系统性筹划, 分散单一、 重复建设等现象比较严重, 造成资源不能有效集中使用, 仪器设备使用效益低下, 维护成本 较高; 同时资金投入不到位, 实验场地狭小, 实验仪器设备落后, 实验室安全环保条件欠缺 等 $^{[1]}$, 阻碍了实验室进一步建设与发展。此外, 大部分高效实验室只对本专业开设实验课 程, 造成实验室设备的闲置 ${ }^{[2]}$ 。

\section{3 实验室师资队伍水平偏低}

受到实验室管理体制的影响，在对实验室技术人员的培养上缺少政策支持，同时师资队 伍在长远发展上缺少激励机制, 造成实验室师资队伍建设普遍弱化, 最终使得参与实验教学 工作的中青年教师和技术管理人员力量不足，业务水平与技术能力参差不齐，难以形成一支 热爱实验工作、懂技术、会管理的知识和年龄结构合理的技术管理队伍，具体表现为：实验 室人员待遇低, 发展空间有限, 使得实验室队伍不稳定, 数量不够, 积极性不高, 不愿意到 实验室工作 ${ }^{[1]}$ 。

\section{2. 开放实验室的必要性}

高校实验室是培养学生实践能力、创新能力、创业能力的重要基地, 尤其是专业实验室 [3-4]。建立适应于应用型-创新型-创业型 “三型” 人才培养的开放实验室, 并对开放实验室建设 及管理模式进行改革是实现 “三型” 人才培养目标的关键, 这对于提高大学生的实践能力、培 养创新意识和创业能力起着极其重要的作用。实验教学在培养学生科学素养和创新能力方面 具有明显的优势, 相对于理论教学具有直观性、实践性、综合性和创新性的特点, 因此, 要 培养高素质的 “三型” 人才, 就必须进行实验教学方法的改革, 而进行实验教学方法的改 革, 其中重要的一点就是开放实验室。

《国家中长期教育改革和发展规划纲要（2010－2020）》中明确提出 “要坚持能力为重 的培养模式, 着力提高学生的学习能力、实践能力、创新能力”。2011年教育部、财政部在 《关于实施高等学校创新能力提升计划的意见》中指出 “创新能力是提高质量的灵魂” , “当今世界, 创新已成为经济社会发展的主要驱动力, 创新能力成为国家竞争力的核心要 素”。构建创新型人才培养模式, 培养具有创新意识和创新能力的高素质人才, 是当前高等 教育的重要任务。

随着《教育部关于全面提高高等教育质量的若干意见》的颁布及创新人才培养、强化实 践育人环节等要求的细化, 如何利用实验室资源来支撑与促进创新人才与创新能力的培养更 成了各高校关注的焦点。因此, 开放实验室的建设直接影响到培养的学生是否符合国家对人 才培养的要求。加强高校开放实验室建设, 充分发挥开放实验室在人才培养方面的积极作 用, 实现以学生为本, 改变高校传统的实验教学管理、运行模式, 结合高校自身的特点和发 展需要, 逐步建立开放型实验室, 使学生养成自主学习的习惯, 并培养创新意识和实践能 力, 为社会培养应用型、创新型、创业型 “三型” 人才奠定基础。

\section{3. 开放实验室的具体措施}

\section{1 建立多层次开放实验室}

无机非金属材料工程专业作为新办专业，为达到学校 “三型” 人才培养目标，更好地服 务地方发展, 在充分调研的基础上提出了建立多层次开放实验室的思路。该实验室涵盖了硅 酸盐分析化学、材料制备与加工、材料高温烧成、材料成型与养护、材料物理性能测试、材 
料力学性能测试、材料耐久性测试、材料粒度分析等不同功能要求的分实验室, 主要用于原 材料成分分析、物料加工制备、烧成、性能测试与耐久性研究等。

\section{2 完善实验室制度}

在严格执行学校有关开放实验室规章制度的基础上，根据材料专业实验室实际，制定和 落实各类开放实验管理人员的岗位责任制, 特别是材料加工制备和高温烧成室等, 落实了诸 如: 《开放实验室安全管理规定》、《开放实验室仪器设备损坏、丢失赔偿管理规定》、《开 放实验室指导教师岗位职责》、《开放实验室仪器设备使用操作规程》和《开放实验室高温 仪器设备使用操作规程》等规章制度, 使开放实验室管理更加规范化和科学化。

\section{3 优化实验室师资队伍}

建立一支结构合理、素质过硬的实验技术队伍是开放实验室建设和管理的重要保障 ${ }^{[5]}$ 。 根据功能性开放实验室的要求, 设立若干个管理团队, 采用主管实验室副院长与教师、教师 与勤工助学学生相结合的分层次管理模式。通过建立多样化的培训方式、合理的聘任制度和 有效的激励机制, 提高实验管理人员的技术水平、业务能力和主动服务意识。每年派出骨干 教师参加不同类别高等院校实验室建设与管理等相关培训或会议, 掌握高校实验室建设和管 理的前沿动态, 提高教师的业务素质。

\section{4 实施本科生导师制}

我校为应用型地方本科院校, 本专业的生源主要来自广东地区, 学生普遍具有思维活 跃、乐于实践等特点, 需要针对上述特点加以正确与合理的引导。以本科生导师制为契机, 本科生在学有余力的情况下, 积极加入了导师负责或所在的科研课题组, 进入了导师所在的 科研实验室, 从事一些导师负责或者是本科生自拟的科研项目。进入实验室后, 本科生与导 师一起开会讨论、设计方案、实验分析、撰写论文, 在此过程中, 学生丰富了自己的书本知 识，培养和激发了专业兴趣。

\section{5 成立科研创新实验小组}

学生根据自己的兴趣爱好, 自愿报名, 教师选拔出3-5人参加创新实验小组, 并由优秀 学生担任小组长, 由有丰富经验的教师担任指导教师。实验内容是由教师设定的, 做一些教 材以外的综合性、设计性、研究性等多层次实验, 其内容涵盖所学的专业理论知识与基本操 作技能，并要具有一定的前沿性。

多年来，材料专业实验室吸收部分优秀学生，早期进入实验室参与教师的科学研究活动。 学生在教师的指导下查阅文献、收集资料, 制定实验方案, 进行较高层次的研究。实验过程 中, 通过教师的指导, 学生可以较快地熟悉科研一般过程, 从中感受科研工作的全部内涵, 在获得知识的同时体会知识的产生过程，培养科学研究的基本规律和思维方法。

\section{6 设置创新学分, 指导申报大学生创新创业训练计划项目}

鼓励学生积极参加开放型实验，对参加开放实验中成绩突出的或完成具有创造性成果的 学生进行奖励, 提高学生参与开放实验室的积极性, 同时, 对顺利实现开放实验室的目的, 即培养高素质创新人才起着关键作用。

在实验过程中发现新问题、新思路的, 鼓励并指导学生申报大学生创新创业训练计划项 目, 通过学校提供的项目资助研究经费, 以学生为主体进行创新实验, 形成开放实验室良性 循环机制, 调动学生的积极性与主动性 ${ }^{[6]}$ 。

通过以上措施可以激发学生学习专业课程的兴趣, 有力地培养了学生的创新精神、实践 能力、团队精神，提高了分析问题和解决问题的能力。 


\section{4. 开放实验室的有益效果}

(1) 开放实验室补充了课堂实验教学的不足, 满足了不同层次学生的要求, 激发了学生 的学习兴趣和学习主动性, 使学生实际动手能力和科研能力等综合素质得到了提高, 创新意 识增强。

(2) 发挥投资效益, 实现资源共享。开放实验室打破了传统实验室的封闭状态，实行最 大范围内的资源共享, 更好地将实验室的实验设备、学术和技术优势提供给进行实验教学、 科研的实验者, 适应了高等教育深化改革的要求。

(3) 基于开放实验室, 充分发挥大学生的想象力和创造力, 激发了学生的创新欲望, 并 且在各级别竞赛活动中取得优异成绩起到积极的促进作用, 从而形成了创新教育的良性循 环。通过近三年开放实验室建设, 学生先后成功申报国家级大学生创新创业训练计划项目3 项、省级大学生创新创业训练计划项目 2 项、校级大学生创新创业训练计划项目 6项; 成功申 报广东省共青团 “攀登计划” 项目 2 项; 作品 “结构梯度型复合透水砖” 获校级大学生课外 科技作品竞赛特等奖, 获 “挑战杯” 广东省大学生课外学术科技作品竞赛终审决赛三等奖; 学生参与撰写完成学术论文10余篇, 授权发明专利3项, 实用新型专利5项。

\section{致谢}

*基金项目 : 2016年广东省本科高校高等教育教学改革项目（粤教高函[2016]236号-475）; 韶关学院教育教学改革研究项目（SYJY20151653、SYJY20161750、SYJY20171811）。

\section{References}

[1] X. H. Wang, J. Wang, H. Y. Li, etc. Research and exploration of construction of open laboratories in colleges and universities, J. Research and Exploration in Laboratory. 32(2013)219-221.

[2] F. Wang, J. Yu. J. Open laboratory in universities and colleges and fostering of students' innovation ability, J. Research and Exploration in Laboratory. 30(2011)320-322.

[3] H. G. Zhang, X. N. Sun, C. W. Ji, etc. Opening laboratory to promote spirit of innovat ion and practice ability of undergraduate students, J. Experimental Technology and Management. 28(2011)16-19.

[4] Y. W. Liang, B. Liu, Y. F. Du. Opening laboratory resources and promoting cultivation of innovative ability, J. Experimental Technology and Management. 30(2013)50-52.

[5] H. W. Jin. Construction of material engineering laboratory in applied local universities, J. Research and Exploration in Laboratory. 35(2016) 237-240.

[6] H. B. Xie, Y. Yang, L. Chen, etc. Discussion on the construction of opening laboratory, J. Experimental Technology and Management. 28(2011)178-180. 